\title{
Desenvolvimento territorial: Uma análise sobre os recursos do Programa Territórios da Cidadania
}

\author{
Marcos Junior Marini \\ Universidade Tecnológica Federal do Paraná - Pato Branco - PR - Brasil \\ ORCID: http://orcid.org/0000-0003-2539-0335 \\ Felipe Polzin Druciaki \\ Universidade Estadual do Centro Oeste - Guarapuava - Paraná - Brasil \\ ORCID: https://orcid.org/0000-0003-0789-0651 \\ Marcio Gazolla \\ Universidade Tecnológica Federal do Paraná - Pato Branco - PR - Brasil \\ ORCID: https://orcid.org/0000-0002-4807-6683 \\ Christian Luiz da Silva \\ Universidade Tecnológica Federal do Paraná - Pato Branco - PR - Brasil \\ ORCID: https://orcid.org/0000-0002-9365-6257
}

\begin{abstract}
Resumo
Este trabalho buscou evidenciar quais foram os montantes destinados pelo governo federal ao Programa Territórios da Cidadania durante sua operacionalização entre 2007 a 2019. Mais especificamente, buscou-se investigar quais processos de desenvolvimento foram gerados a partir desses investimentos. Para tanto, foram analisados todos os valores encontrados nos portais eletrônicos oficiais do Governo Federal referente à política pública do PTC entre 2007 e 2019. Os principais resultados mostram que de 2007 a 2013 foram encontrados apenas dados referentes à elaboração do Plano Territorial de Desenvolvimento Rural Sustentável (PTDRS) e, de 2014 a 2019, todos os dados referentes aos recursos operacionalizados pelo PTC. Os dados também evidenciam que os estados das Regiões Norte e Nordeste são prioritários no recebimento dos recursos, estando isso de acordo com o que prevê a política territorial. Por fim, os dados demonstram que os montantes de recursos são inferiores aos encontrados em literaturas similares e basicamente todas as ações financiadas pelo PTC estão ligadas ao desenvolvimento territorial rural.
\end{abstract}

Palavras-chave: Desenvolvimento Territorial. Programa Territórios da Cidadania. Política Pública. 


\section{Territorial development: An analysis of the resources of Territórios da Cidadania Program} Abstract

This work sought to highlight the amounts allocated by the federal government to the Territories of Citizenship program during its operation between 2007 and 2019. More specifically, we sought to investigate which development processes were generated from these investments. To this end, all the values found in the official electronic portals of the Federal Government regarding the public policy of PTC between 2007 and 2019 were analyzed. The main results show that from 2007 to 2013 only data were found referring to the preparation of the Territorial Plan for Sustainable Rural Development (PTDRS) and, from 2014 to 2019, all data referring to resources operated by PTC. The data also show that the states of the North and Northeast regions are a priority in receiving resources, which is following what the territorial policy provides. Finally, the data show that the amounts of resources are lower than those found in similar literature and all actions financed by PTC are linked to rural territorial development.

Keywords: Territorial Development. Programa Territórios da Cidadania. Public Policy.

\section{Desarrollo territorial: un análisis de los recursos del Programa Territórios da Cidadania Resumen}

Este trabajo buscó resaltar los montos asignados por el gobierno federal al programa Territorios de Ciudadanía durante su operación entre 2007 y 2019. Más específicamente, buscamos investigar qué procesos de desarrollo se generaron a partir de estas inversiones. Con este fin, se analizaron todos los valores encontrados en los portales electrónicos oficiales del Gobierno Federal con respecto a la política pública de PTC entre 2007 y 2019. Los principales resultados muestran que de 2007 a 2013 solo se encontraron datos referentes a la preparación del Plan Territorial para el Desarrollo Rural Sostenible (PTDRS) y, de 2014 a 2019, todos los datos referentes a recursos operados por PTC. Los datos también muestran que los estados de las regiones Norte y Nordeste son una prioridad en la recepción de recursos, lo cual está de acuerdo con las disposiciones de la política territorial. Finalmente, los datos muestran que las cantidades de recursos son más bajas que las encontradas en literatura similar y básicamente todas las acciones financiadas por PTC están vinculadas al desarrollo territorial rural.

Palabras clave: Desarrollo territorial. Programa de Territórios da Cidadania. Política pública.

\section{Introdução}

A perspectiva do desenvolvimento econômico é dinâmica e vem mostrando diferentes reinterpretações do paradigma clássico em que desenvolvimento é função do produto de um determinado lócus. Com o passar dos anos, percebeu-se que o espaço é um fator social, político e econômico importante para pensar-se o desenvolvimento. Principalmente a partir do pós-guerra, na década de 1950, proliferaram-se estudos sobre o papel do espaço no desenvolvimento econômico de diferentes regiões e seu impacto na sociedade (FERRERA DE LIMA, 2012; CAPELLO, 2008).

No Brasil, o pensamento econômico de Furtado já alertava para problemas socioeconômicos desde a colonização portuguesa do século XVI. O país cresceu a partir do modelo primário exportador, que concentrava contingente populacional e financeiro em algumas localidades em detrimento de outras (FURTADO, 1973; SANTOS, 2008). 
A composição do território brasileiro é a soma de diversos espaços marcados por características sobremaneira distintas em uma composição socioeconômica e espacial desigual. O resultado da sedimentação econômica brasileira evidencia na atualidade importantes desafios, não para equalizar uma maneira utópica de alta qualidade de vida a todos, mas pelo menos atenuar a severa discrepância entre territórios de alto e baixo dinamismo econômico.

O processo de desenvolvimento depende de diversos fatores e leva em conta características únicas de cada espaço, surge no tempo de forma incerta e ocorre em lugares diferentes em intensidades diferentes (PERROUX, 1964). O Estado pode ser um agente de indução para o processo de desenvolvimento ao utilizar-se dos mecanismos da política pública. Segundo Lynn (1980), entende-se por políticas públicas ações do governo que visam produzir efeitos específicos na sociedade. De modo geral, as políticas públicas amplificam os resultados de suas ações, por isso está interligada ao Estado, economia, política e sociedade (SOUZA, 2006).

Principalmente a partir da segunda metade dos anos de 1990 no Brasil e no mundo, as políticas públicas em prol do desenvolvimento territorial vêm ganhando espaços e sendo sistematizados a partir da discussão da pobreza rural e posteriormente dos territórios menos dinâmicos (FAVARETO, 2009). Segundo Pecqueur (2009), a concepção das políticas de desenvolvimento territorial mostra a necessidade de interação da política com atores públicos, privados e associativos, a fim de uma melhor aderência da política em relação ao seu contexto.

A problemática deste artigo buscou responder quais foram os montantes operacionalizados via Programa Territórios da Cidadania (PTC) e como estes recursos engendraram processos de desenvolvimento nos territórios. A resposta à esta pergunta está condicionada ao objetivo principal que buscou evidenciar quais foram os montantes destinados pelo governo federal ao programa Territórios da Cidadania durante sua operacionalização entre 2007 a 2019. Mais especificamente, buscou-se investigar quais processos de desenvolvimento foram gerados a partir desses investimentos.

Os questionamentos supracitados justificam-se pela aresta científica em relação a avaliação dos recursos destinados pela política pública do Programa Territórios da Cidadania de forma abrangente em todos os territórios brasileiros. Estes resultados permitirão lançar luz sobre quais estratégias do desenvolvimento estão pautados os respectivos investimentos territoriais.

É importante ressaltar que outros trabalhos abordando a questão da política pública envolvendo os Territórios da Cidadania são encontrados na literatura ${ }^{1}$, porém, percebe-se uma maior dificuldade em encontrar trabalhos que tragam o montante investido pela política pública de forma sistematizada e agregada para todo o país e todo o período de existência da mesma.

Este trabalho está dividido em três partes além desta introdução e das considerações finais. Na segunda seção encontra-se uma breve síntese da literatura acerca dos objetos de estudo deste trabalho: política pública e desenvolvimento

\footnotetext{
${ }^{1}$ Dentre os diversos estudos, destaca-se àqueles essencialmente voltados ao PTC, que se encontram no repositório do Sistema de Gestão Estratégica (SGE), no endereço:

<http://sge.mda.gov.br/bibli/bibli_re/>.
} 
territorial. Na segunda seção são evidenciados os métodos envolvidos para coleta e tratamento dos dados utilizados. Na última seção são expostos os principais resultados encontrados a partir da análise dos dados em torno da política de desenvolvimento territorial.

\section{Desenvolvimento territorial}

Estar em um patamar de bom desenvolvimento socioeconômico é meta de diversos, se não todos, os países, bem como as suas regiões. O desenvolvimento, em âmbito geral, está ligado a passagem de um estágio inicial de um processo a um estado superior, mais adiantado, a um aumento de condições, ampliação de capacidades, seja individual ou coletiva de acesso a bens, serviços e qualidade de vida (BRANDÃO, 2007). Essa noção de tensão não é novidade e vem sendo discutida desde os clássicos da ciência econômica como Smith, Ricardo, Malthus e Mill e, como o próprio radical da palavra indica, ainda está em construção, em desenvolvimento.

Um conceito neoclássico sobre desenvolvimento esclarece que o fenômeno é "la combinaison des changements mentaux et sociaux d'une population qui la rendent apte à faire croître cumulativement et durablement son produit réel et global" (PERROUX, 1964, p. 155). Essa visão de Perroux ainda é bastante aceita academicamente por agrupar questões sociais e econômicas no que resultaria numa melhor qualidade de vida dos indivíduos.

Outros autores como Jean (2008) traz uma concepção de desenvolvimento baseado na participação, pois para o autor "pas de développement sans démocratie et pas de démocratie sans développement. Car il a bel et bien là un lien de causalité circulaire" (JEAN, 2008, p. 16). Neste sentido, a noção de espaço desenvolvido perpassa as relações locais de participação nas ações do território, o que foi levado em consideração pelo Governo Federal Brasileiro, para criação da política pública dos Territórios da Cidadania, desconcentrando, em tese, as estratégias nacionais em organismos espaciais menores, os Territórios da Cidadania, a partir da construção democrática dos atores envolvidos no processo.

Como não há consenso estático de um conceito que é dinâmico, para se compreender de forma mais completa o processo de desenvolvimento, faz-se necessário delimitar sua abrangência ou objeto de estudo. Desde os anos de 1970 o processo de mundialização ou globalização são preponderantes na análise econômica e somente a partir dos anos de 1980 retomam-se as relações de proximidade entre atores locais, conceito já difundido por Alfred Marshall com os distritos industriais (PECQUEUR; BENKO, 2001).

Para Jean (2008) o território é um conceito ainda pouco explorado pelos economistas e cientistas sociais. Esta unidade de análise é carregada de características únicas, incluindo questões históricas, sociais, culturais, econômicas, ambientais e geográficas. Cada território possui uma identidade e sua composição é produto da ação de sujeitos pertencentes a este lócus.

Entender o território é tarefa complexa, porém, autores da geografia e da economia, além de outros, são consistentes na ideia de que o território é um espaço para criação e reprodução do capital a partir de uma integração entre o local e o global (RULLANI, 1997; ANASTASIA; CORÒ, 1996). Neste sentido, para Rullani (1997, 
p. 89) o território é “(...) um lugar particular (local) e, ao mesmo tempo, um nexo entre aquele lugar e todos os outros possíveis lugares (global)”.

A complexidade territorial é multidisciplinar, pois são necessários diversos focos para representar o lugar como centralidade, dando importância à antropologia, sociologia, botânica, sustentabilidade e filosofia para evitar de se pensar na lógica do capital, em que o local está subordinado ao global (ESCOBAR, 2005). O conceito de desenvolvimento territorial amplia-se destas definições anteriores, trazendo consigo relações materiais e imateriais disponíveis dentro de um espaço. Boisier (2004, p. 3), resume que:

\begin{abstract}
desarrollo territorial, presupu Estado, como siempre, el crecimiento y por tanto la generación de excedentes; una mirada enfocada a las diversas formas de capital que es posible encontrar en un territorio (organizado) y que, si adecuadamente articuladas entre sí, deberían casi inexorablemente producir desarrollo. Tal articulación sería el resultado de poner en valor la forma más importante de capital que se encuentra en el seno de toda comunidad: el capital sinergético.
\end{abstract}

Nesse contexto, o território é um lócus geográfico distinto, caracterizado por questões sociais, políticas e econômicas convergentes e divergentes e que o desenvolvimento territorial pressupõe questões materiais e imateriais únicas a cada espaço.

Os dispositivos do Estado para promoção do desenvolvimento nem sempre abarcam a totalidade dos seus sujeitos, excluindo parcela da sociedade do processo construtivo de um território com melhor qualidade de vida e mais dinâmico economicamente. Paradoxalmente, o Estado também é responsável pelas disparidades sociais e econômicas e a fim de atenuar situações de baixo dinamismo econômico, pobreza e outros problemas sociais, uma ferramenta amplamente utilizada é a política pública.

\title{
2.1 Políticas Públicas e o Programa Territórios da Cidadania
}

A política pública pode ser entendida como "The study of politics is the study of influence and the influential” (LASSWELL, 1936, p. 13). Uma definição mais enxuta sobre public policy pode ser encontrada no trabalho de Thomas Dye, para o autor a política pública está relacionada a "what governments do, why they do and what difference it makes". Ademais, Dye (1984, p. 3) ressalta que "política pública é qualquer coisa que um governo escolhe fazer ou não fazer".

Conceituar e denominar a importância das políticas públicas atravessa diversos campos teóricos, porém, a visão geral do tema está ligada aos governos, que corresponde a natureza da política pública. Para Souza (2006), as ações das políticas públicas reverberam na sociedade e na economia e isto mostra a aderência da política pública no processo de desenvolvimento socioeconômico de uma região ou território e suas inter-relações.

A política pública do PTC, conforme sua legislação, no seu $\S 2^{\circ}$, estabelece que os Municípios que compõem os Territórios da Cidadania são agrupados segundo critérios sociais, culturais, geográficos e econômicos e reconhecidos pela sua população como o espaço historicamente construído ao qual pertencem, com 
identidades que ampliam as possibilidades de coesão social e territorial (BRASIL, 2008).

De acordo com Galvanese (2018, p. 128), no Brasil a discussão regional e territorial ganha força após os anos 2000. Em 2002 e, já no início do governo, a redução das desigualdades regionais figurava entre os principais objetivos do PPA 2004/2007 (Plano Brasil de Todos), ao lado da inclusão social, geração de emprego e renda, redução de desigualdades e fortalecimento da cidadania e da democracia.

Foi a partir destas discussões que surge a Política Nacional de Desenvolvimento Regional (PNDR), o Estudo da Dimensão Territorial para o Planejamento (EDTP) e o Programa Territórios da Cidadania (PTC), este último objeto de estudo deste trabalho. O PTC foi criado por decreto presidencial em 25 de fevereiro de 2008, de forma integrada pelos diversos órgãos do Governo Federal, objetivando a melhoria na qualidade de vida dos indivíduos e na ampliação de acesso aos bens e serviços públicos, como uma política pública (BRASIL, 2008).

Antes do PTC, a iniciativa mais próxima desta política foi o Programa Desenvolvimento Sustentável de Territórios Rurais (PRONAT) implementado pela Secretaria de Desenvolvimento Territorial (SDT), em 2003. O PRONAT contava com a parceria de diversas instituições da sociedade civil, além dos governos federal, estaduais e municipais. O PRONAT contava com colegiados de âmbito territorial, fóruns constituídos em cada território por instituições da sociedade civil e do poder público, responsáveis pelo planejamento territorial, pela articulação institucional, elaboração de propostas e projetos técnicos, acompanhamento e controle social das ações do programa e de outras políticas públicas que concorrem para o desenvolvimento sustentável dos territórios (MDA, 2010).

Segundo Barcelar (2014), desde a segunda metade do século XX no Brasil a estratégia de investimento do Estado tem sido o investimento em setores pesados ou de infraestrutura. A partir disso, na década de 1990, inicia-se um processo de gradual liberalização da economia brasileira em que se diminui o peso do Estado como fomentador de atividades produtivas baseado na globalização, reestruturação produtiva e a financeirização das riquezas.

Ainda segundo a autora, é importante que haja descentralização política e do poder para ampliar a rede democrática de participação de baixo para cima. Porém, municípios sozinhos não conseguem articular essas demandas sociais, há necessidades de políticas públicas para integrar os âmbitos municipais, estaduais e federais. Exatamente como ocorre com o funcionamento da política pública do PTC, que funcionava interagindo entre as três esferas e congregando os atores sociais de modo participativo.

No desenho do Programa estão previstas instâncias territoriais e de articulação inter federativa; um nível local, os Colegiados; um nível estadual, o Comitê de Articulação Estadual (CAE); e um nível nacional, o Comitê Gestor Nacional. O CAE congrega gestores municipais, estaduais e federais, por Estado, para monitorar e identificar os gargalos e soluções das políticas públicas em curso nos territórios (BUTTO; BEMERGUY, 2014).

Esse desenho institucional permite uma melhor governança ao PTC a partir da interação dos atores envolvidos em seus territórios. O papel do Estado, neste sentido, não é reprimido, mas sim descentralizado e democratizado pela participação de todos os envolvidos. Os fóruns territoriais são arenas em que se 
tomam decisões para o território visando a melhoria nos índices socioeconômicos. Mesmo assim, a função do Estado para promover essa interação é fundamental, o investimento público é o único caminho para o bonding necessário aos atores. Além disso, autores como Velasco, (1996) defendem que o Estado deve suprir as regiões com sistema educacional, relações empresariais e industriais e infraestrutura para que se crie atrativos no território, o que vai de acordo com as representações de Pecqueur e Benko (2001) sobre atratividade territorial.

Nota-se aqui a estrutura central do programa, levando em consideração os aspectos multifacetados da análise territorial, bem como a importância dos atores que fazem parte dos territórios. O objetivo central do programa foi promover a aceleração da superação da pobreza e desigualdades sociais no meio rural, contemplando as questões de gênero, raça e etnia por meio da deliberação democrática em Conselhos Territoriais para construção de agendas comuns aos atores do território, conforme pode ser visto no Quadro 1 (BRASIL, 2008).

Quadro 1 - Objetivos do PTC estabelecidos no decreto 25/02/2008.

I - Integração de políticas públicas com base no planejamento territorial;

II - Ampliação dos mecanismos de participação social na gestão das políticas públicas de interesse do desenvolvimento dos territórios;

III - ampliação da oferta dos programas básicos de cidadania;

IV - Inclusão e integração produtiva das populações pobres e dos segmentos sociais mais vulneráveis, tais como trabalhadoras rurais, quilombolas, indígenas e populações tradicionais;

V - Valorização da diversidade social, cultural, econômica, política, institucional e ambiental das regiões e das populações.

Fonte: BRASIL (2008).

Os territórios escolhidos pelo extinto Ministério do Desenvolvimento Agrário (MDA) são, em sua grande parte, rurais e possuem problemas estruturais. A gestão do PTC era protagonizada pelo Comitê Gestor Nacional, seguido pelo Comitê de Articulação Estadual e pelo Colegiado Territorial, o qual é composto paritariamente por representantes governamentais e pela sociedade civil organizada em cada território. Assim, é o Colegiado Territorial que elabora todo o ciclo de gestão de planejamento, seguindo os pressupostos já citados contidos na teoria do DT, correspondendo a uma ação a partir dos atores, visando melhorar a qualidade de vida dos indivíduos pertencentes a estes territórios (BUTTO; BEMERGUY, 2014).

Os pilares do PTC estão direcionados à atuação participativa dos atores territoriais, e não a políticas top-down. Essa característica é coerente com os pressupostos teóricos do desenvolvimento territorial ao envolver os seus participantes nas ações dos seus próprios espaços. Desta maneira, criou-se então 120 territórios no Brasil, pertencentes ao PTC, que fazem parte da política pública objetivando aumentar o dinamismo econômico e a melhora de vida dos indivíduos.

Os municípios pertencentes ao PTC possuem uma diretriz de planejamento territorial, denominado de Plano Territorial de Desenvolvimento Rural Sustentável (PTDRS) que é uma ferramenta utilizada pelos atores sociais dentro da estrutura de governança desse programa. O PTDRS engloba diversos 'eixos' prioritários de 
desenvolvimento que visam a melhoria na qualidade de vida da população dos municípios a partir de uma participação democrática e colaborativa.

Diante do exposto, observa-se que o PTC trouxe significativas melhorias para o debate do desenvolvimento territorial, principalmente em âmbito rural, que acabou sendo seu foco. Berdegué e Favareto (2020), defendem que no PTC houveram inegáveis avanços, destacando a mobilização dos atores e ampliação das iniciativas, bem como novas estruturas de governança. Porém, ainda com dificuldades em entender o plano no longo prazo e a baixa diversificação produtiva dos territórios.

Outros fatores interessantes para problematizar a atuação do PTC, está ligado à sua atuação quase exclusiva no âmbito rural, deixando os atores representantes do comércio e serviços descobertos da atuação da política, pouca criatividade na criação e implementação de ações voltadas a promoção da sustentabilidade territorial (GALVANESE, 2019.; DRUCIAKI, 2016).

Ainda sobre a dinâmica do PTC, Valencia et al (2020), também reportam diversos fatores positivos nos programas de desenvolvimento territorial relacionados à participação e organização dos atores, mas chamam atenção para a necessidade da reorganização dos Colegiados Territoriais, os quais foram se perdendo ao longo do tempo nos territórios estudados. Ademais, ressalta-se que há uma vasta bibliografia ${ }^{2}$ que discorre sobre o funcionamento e avaliação do PTC, porém, não como um todo, mas em territórios pontualmente selecionados.

\section{Metodologia da Pesquisa}

Esta pesquisa, de acordo com seu objetivo, busca investigar o destino e o montante financeiro total disponibilizado pelo Programa Territórios da Cidadania (PTC), bem como analisar quais os processos de desenvolvimento foram gerados a partir das ações desta política pública.

Em relação aos procedimentos metodológicos, o artigo pode ser categorizado como uma pesquisa exploratória, baseada em fontes secundárias, a partir do uso da técnica de pesquisa documental. Adicionalmente, quanto ao tratamento dos dados, caracteriza-se ainda pela abordagem quantitativa, devido ao fato de que os dados analisados são passíveis de quantificação e análise estatística básica (GIL, 2008).

Os dados disponíveis referentes ao PTC são de difícil acesso, pois estão fragmentados entre os 120 territórios criados. Muitos destes contam com avaliação científica, contudo, uma limitação é a falta de critério para avaliação. Druciaki (2016) verificou, por exemplo, que no Território Paraná Centro, não há mecanismos de avaliação, muito menos controle por parte dos gestores dos territórios, o que deixa uma lacuna no programa. O critério da coleta de dados foi a disponibilidade pública dos dados em bases oficiais. Estes foram extraídos do sítio eletrônico oficial do Governo Federal $^{3}$, incluindo todos os valores referentes à política pública

2 Vide biblioteca do Sistema de Gestão Estratégica do MDA no sítio <http://sge.mda.gov.br/bibli/bibli_re/>

${ }^{3}$ http://www.portaltransparencia.gov.br/programas-de-governo/22-territorios-dacidadania?ano $=2015$ 
denominada Programa Territórios da Cidadania e/ou recursos de apoio ao Plano Territorial de Desenvolvimento Rural Sustentável (PTDRS), a qual pode ser considerada como uma ferramenta de planejamento e apoio ao PTC.

\section{Mapa 1 - Localização dos Territórios da Cidadania nas Macrorregiões brasileiras.}

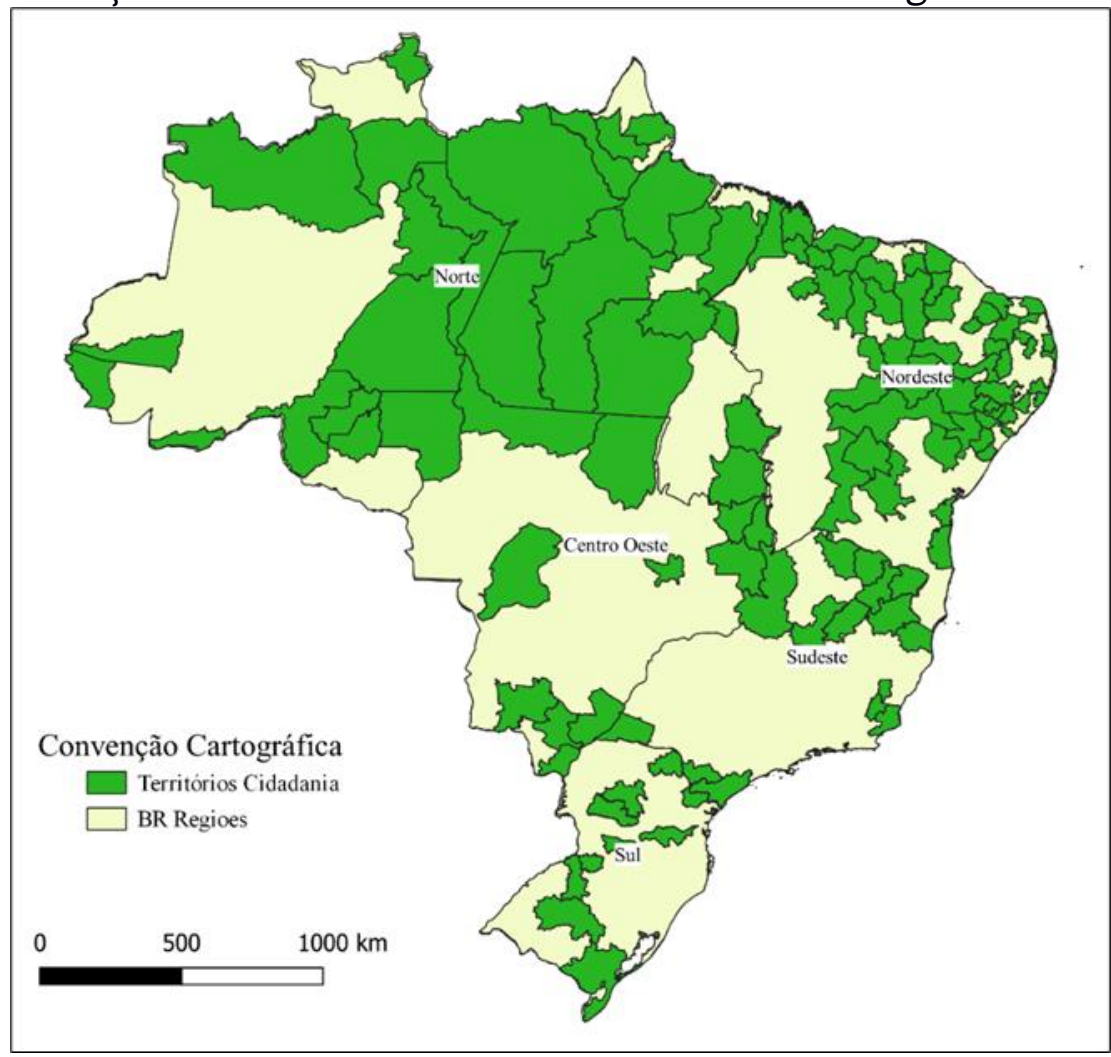

Fonte: MDA (2010).

Em relação ao cenário desta política pública, ressalta-se que o PTC foi criado pelo decreto de 25 de fevereiro de $2008^{4}$, visando melhorar a qualidade de vida em geral de municípios com baixo dinamismo econômico e social, aglomerando-os em territórios. Ao todo, constituíram-se 120 territórios no Brasil, conforme pode ser visto no Mapa 1.

Percebe-se, conforme o Mapa 1, que a concentração dos Territórios da Cidadania ocorreu principalmente nas Regiões Norte e Nordeste do Brasil, o que pode ser considerado coerente com o proposto metodologicamente pelo decreto, ao impactar preferencialmente os municípios de menor dinamismo econômico. $\mathrm{O}$ PTC foi escolhido para ser objeto deste estudo por ser o único esforço de política pública para o desenvolvimento territorial brasileiro, bem como pela escassez de uma análise mais integrada e geral desta política na literatura, em nível de país.

Destaca-se ainda que nos anos de 2008 a 2013 foram encontrados os valores totais empenhados, liquidados e pagos. Contudo, no espaço temporal mais recente, entre os anos de 2014 até 2019, encontrou-se 952 ocorrências de valores monetários; dados detalhados por programa, subprograma e ação por instituição responsável pelo repasse das verbas em uma escala de mês a mês. Todos os valores

${ }^{4}$ https://www.planalto.gov.br/ccivil_03/_at02007-2010/2008/dnn/dnn11503.htm 
foram deflacionados pelo Índice Geral de Preços - Mercado (IGP-M), a valores de dezembro de 2019. O IGP-M é um índice geral de inflação para comparar, ao longo do tempo, o poder de compra da moeda nacional. Trata-se de um índice calculado pelo Instituto Brasileiro de Economia, vinculado à Fundação Getúlio Vargas (FGV, 2020).

\section{Análise dos recursos investidos e do desenvolvimento gerado pelo PTC}

O papel do Estado na formulação e implementação de políticas públicas é preponderante no que diz respeito ao desenvolvimento econômico e social das regiões. O PTC entra na chamada agenda social do governo, objetivando a superação das condições de desigualdade econômica e social, inclusive no meio rural, no que diz respeito também às questões de gênero, etnia e raça, por meio da execução de um planejamento participativo organizado via Colegiado Territorial (BUTTO; BEMERGUY, 2014). Ainda, segundo as autoras, a dimensão desta política é evidenciada pela sua abrangência, que representa 33\% do total de municípios brasileiros, aproximadamente 42,4 milhões de pessoas e $46 \%$ da população rural. Em termos de segmentos atendidos, destaca-se $47 \%$ da agricultura familiar, $67 \%$ dos assentados da reforma agrária, $66 \%$ das comunidades quilombolas, $52 \%$ das terras indígenas e $54 \%$ dos pescadores habitam esses territórios (BUTTO; BEMERGUY, 2014).

Vale ainda ressaltar que, essa aglomeração corresponde à 120 territórios distribuídos pelas cinco macrorregiões brasileiras conforme exposto na Tabela 1. Outra questão importante é o foco no rural que o programa trouxe em seu bojo, questão comentada por Druciaki (2016), ao afirmar que grande parte das ações contidas no PTDRS dos territórios tem fins rurais, mas que o território não é formado apenas por atores e áreas rurais.

Tabela 1 - Total de PTC's e municípios por Macrorregião brasileira

\begin{tabular}{c|c|c|c|c}
\hline Macrorregiões & Territórios & $\%$ & Municípios & $\%$ \\
\hline Nordeste & 56 & 46,7 & 939 & 50,7 \\
Norte & 26 & 21,7 & 254 & 13,7 \\
Sudeste & 16 & 13,3 & 277 & 15 \\
Centro-Oeste & 12 & 10 & 137 & 7,4 \\
Sul & 10 & 8,3 & 244 & 13,2 \\
\hline Total & $\mathbf{1 2 0}$ & $\mathbf{1 0 0} \%$ & $\mathbf{1 8 5 1}$ & $\mathbf{1 0 0 \%}$ \\
\hline
\end{tabular}

Fonte: BRASIL (2008).

Em relação à Tabela 1, percebe-se a grande concentração dos territórios na Região Nordeste e Norte, com aproximadamente $68,4 \%$ do total brasileiro, devido as características de baixo dinamismo econômico e social dessas regiões. Dentre diversas metodologias para mensurar os níveis de desenvolvimento econômico e social disponíveis na literatura, destaca-se, no caso brasileiro, o Índice Firjan de Desenvolvimento Municipal (IFDM), calculado pelo sistema FIRJAN desde 2006 no Brasil. Ressalta-se que a vantagem do IFDM em comparação ao Índice de Desenvolvimento Humano Municipal (IDH-M), mensurado pelo Programa das Nações Unidas para o Desenvolvimento (PNUD), é a periodicidade, uma vez que 
esse é decenal, sendo que o último relatório do IDH-M foi publicado em 2010. Já o IFDM foi publicado em 2018 com base em dados de 2016, conforme pode ser observado no Mapa 2.

Mapa 2 - Distribuição dos municípios brasileiros por grau de desenvolvimento do IFDM Emprego e Renda entre 2006 e 2016.

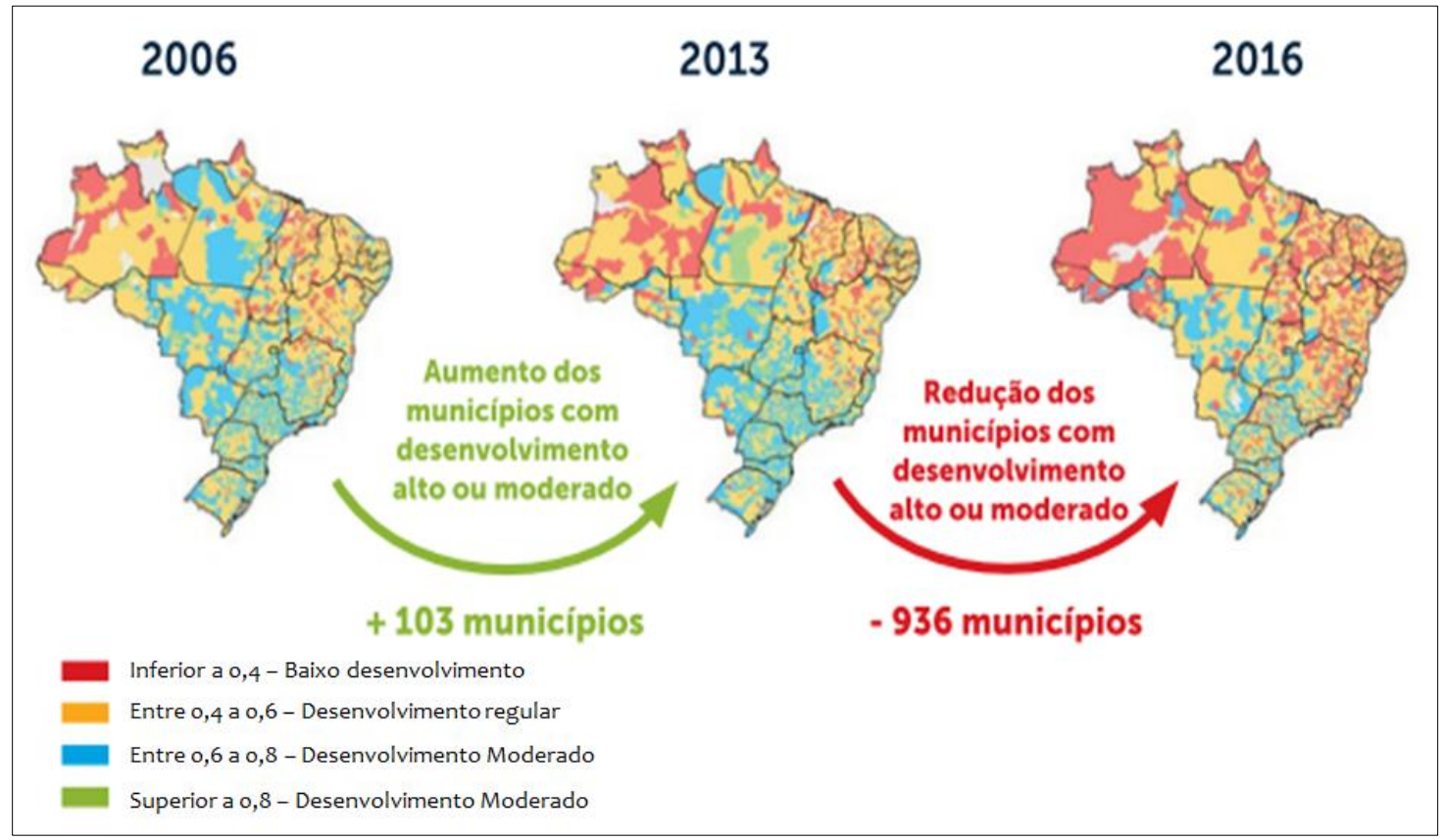

Fonte: FIRJAN (2018).

Conforme o Mapa 2, de 2006 a 2013 houve melhoria na qualidade de vida da população brasileira em geral, mesmo que os dados do mapa mostrem exclusivamente os indicadores de emprego e renda, ao se analisar os outros níveis, saúde e educação, o comportamento é similar (FIRJAN, 2018). Porém, entre 2013 e 2016, ocorreu uma redução nesses índices, voltando a aumentar a desigualdade socioeconômica nos territórios brasileiros. Ademais, o Mapa 2 mostra que os municípios mais afetados pela redução estão concentrados nas Regiões Norte e Nordeste. Isso é um dos motivos que o número de PTC's e municípios atendidos sejam maiores nestas regiões, justificando a ação da política pública como indutora do desenvolvimento e atenuante das disparidades socioeconômicas.

\subsection{Investimento público para o desenvolvimento}

Os investimentos econômicos não são os únicos atrativos territoriais, existem outros tangíveis e intangíveis (BOISIER, 2004). Porém, a operacionalização do PTC necessita de uma irrigação no sistema institucional via recursos federais. Esses recursos são organizados por cerca de 22 órgãos e entidades federais além dos Ministérios do Desenvolvimento Agrário (MDA), Ministério do Planejamento, Orçamento e Gestão (MPOG) e da Casa Civil da Presidência da República (CC/PR).

Os dados orçamentários do PTC se mostram divergentes na literatura já existente e no encontrado no sítio oficial do governo federal. Segundo Favareto (2009), pesquisador da área de desenvolvimento territorial rural, verificou-se que o 
orçamento para 2008 para o PTC estava orçado em R\$12,9 bilhões. Já Galvanese (2018), mostra em trabalho recente, que em 2009 o PTC realizou 180 ações, investindo cerca de R\$ 23 bilhões de reais. Para Butto e Bemerguy (2014), em 2013 foram previstas 71 ações e um investimento de $R \$ 7,13$ bilhões em que inclusive 0 recurso superou o previsto ao final do exercício totalizando $R \$ 8,7$ bilhões. Estimativas para 2014 da própria SDT, na época, estipularam a meta de $\mathrm{R} \$ 8,4$ bilhões.

Por outro lado, ao verificar os valores investidos pelo Programa de Governo $\mathrm{n}^{\circ} 22$ - Programa Territórios da Cidadania, disponíveis na fonte oficial de dados ${ }^{5}$, constatam-se volumes sobremaneira menores que outros valores divulgados por trabalhos anteriores de diversos autores. Isso pode estar ligado basicamente a duas questões: a) grande parte dos trabalhos trazem valores monetários que podem estar trabalhando com dados que, no momento daquela pesquisa, ainda correspondem a projeções a serem realizadas; b) a segunda questão pode estar ligada ao fato de que outros recursos tenham sido direcionados ao PTC, porém, por outra via, a não ser a rubrica do programa 22 ou a ação 2A99 de Apoio à Gestão dos Planos Territoriais de Desenvolvimento Rural Sustentável (PTDRS), no sítio da transparência da união. Os valores disponibilizados estão divididos entre empenhados, liquidados, pagos e restos a pagar e serão analisados conforme ordem cronológica, de acordo com a Tabela 2.

Tabela 2 - Montantes em reais destinados ao programa Territórios da Cidadania via Apoio à Gestão dos Planos Territoriais de Desenvolvimento Rural Sustentável (PTDRS), entre 2007 e 2013. Valores em milhões de reais.

\begin{tabular}{c|c|c|c|c}
\hline Ano & Valor Empenhado & Valor Liquidado & Valor Pago & IGPM \% \\
\hline 2007 & 14,8 & 8,0 & 8,0 & 2,18 \\
2008 & 33,0 & 24,8 & 24,8 & 2,03 \\
2009 & 20,6 & 3,8 & 3,8 & 1,85 \\
2010 & 48,8 & 43,8 & 40,2 & 1,88 \\
2011 & 27,1 & 11,6 & 11,6 & 1,69 \\
2012 & 34,2 & 13,9 & 3,9 & 1,60 \\
2013 & 5,3 & 0,3 & 0,3 & 1,49 \\
Média & 26,2 & 15,1 & 14,6 & - \\
\hline Total & $\mathbf{1 8 3 , 7}$ & $\mathbf{1 0 6 , 3}$ & $\mathbf{1 0 2 , 6}$ & - \\
\hline
\end{tabular}

Fonte: Elaborado pelos autores com base no Painel do Orçamento Federal (2020). Valores em preços constantes pelo índice Geral de Preços Médios (IGPM) de dezembro de 2019.

Verifica-se na Tabela 3, que os valores efetivamente pagos ao programa Territórios da Cidadania exclusivamente via Apoio à Gestão dos PTDRS ficaram aquém daqueles valores inicialmente empenhados. Entre os anos analisados os montantes não obtiveram um padrão de empenhados e pagos. Em 2007 foi pago pouco mais da metade do valor empenhado, no ano subsequente os valores pagos contabilizaram mais de $75 \%$ do empenhado. Nos anos seguintes, o comportamento das variáveis também mostrou grandes diferenças. A falta de um padrão coloca em

${ }^{5}$ http://www.portaltransparencia.gov.br/programas-de-governo/22-territorios-da-cidadania?ano=2015 (dados disponíveis para os anos de 2015 a 2019). 
evidência a fragilidade da política do PTC, uma vez que em tempos é amplificada, em outros é desacelerada.

Em média, apenas 55,7\% dos valores empenhados foram efetivamente pagos durante os 7 anos disponíveis da série histórica. Outra questão que chama atenção é o aumento do valor pago em 2010 em relação a 2009, que salta de $\mathrm{R} \$$ 3,8 milhões para $\mathrm{R} \$ 40,2$ milhões e nos anos subsequentes diminui novamente. Provavelmente este fato ocorrera devido a elaboração dos PTDRS, que foram confeccionados a partir da criação dos territórios, entre 2008 a 2011, quando grande parte dos planejamentos começam a ser publicados e seguidos. De qualquer forma, o apoio estatal ao planejamento é também apoio efetivo ao desenvolvimento dos territórios brasileiros e, neste sentido, observa-se que entre os 7 anos analisados, pouco mais de R\$102 milhões foram destinados a 120 territórios, distribuídos em 1852 cidades, com um valor médio por território cerca de $\mathrm{R} \$ 850$ mil, cerca de $\mathrm{R} \$$ 14,57 milhões por ano por território. Adicionalmente, observa-se ainda que nestes anos não houve restos a pagar desta ação do governo.

Para Druciaki (2016), analisando o Território Paraná Centro, o PTDRS serve como diretriz base do planejamento dos territórios. Porém, ainda segundo esse autor, "percebe-se que o PTDRS de 2011 foi pouco usado pelos seus representantes e a falta de operacionalização, monitoramento e readequação do plano compromete a eficácia do processo de desenvolvimento territorial" (DRUCIAKI, 2016, p. 118).

Para os anos de 2014 a 2019 o panorama é diferente. Para estes anos, os dados tabulados foram exclusivamente aqueles vinculados ao Programa de Governo 22 -PTC. Neste período, foram 952 ocorrências, divididas mês a mês por: Órgão superior, órgão vinculado, unidade gestora, área de atuação, subfunção, ação orçamentária, elemento de despesa e modalidade de despesa, conforme exposto na Tabela 3. A Tabela 3 apresenta precisamente quais montantes foram destinados para o PTC, disponibilizados oficialmente através do Portal da Transparência da União. Todos os valores foram corrigidos pelo IGPM para preços correntes de dezembro de 2019. 
Tabela 3 - Valores em reais empenhados, liquidados, pagos e restos a pagar de 2014 a 2019 destinados ao Programa de Governo 22 - Territórios da Cidadania (valores em milhões de reais).

\begin{tabular}{c|c|c|c|c|c}
\hline Ano & $\begin{array}{c}\text { Valor } \\
\text { Empenhado }\end{array}$ & $\begin{array}{c}\text { Valor } \\
\text { Liquidado }\end{array}$ & Valor Pago & $\begin{array}{c}\text { Valor } \\
\text { Restos a } \\
\text { Pagar Pagos }\end{array}$ & IGPM \% \\
\hline 2014 & 227,31 & 41,90 & 23,41 & 62,96 & 1,41 \\
2015 & 122,04 & 35,95 & 22,97 & 100,83 & 1,36 \\
2016 & 87,74 & 48,21 & 44,71 & 110,14 & 1,23 \\
2017 & - & - & - & 44,91 & 1,15 \\
2018 & - & - & - & 8,77 & 1,15 \\
2019 & - & - & - & 6,15 & 1,07 \\
\hline Média & $\mathbf{1 4 5 , 7}$ & 42 & $\mathbf{3 0 , 3}$ & $\mathbf{5 5 , 6}$ & - \\
\hline Total & 437,09 & $\mathbf{1 2 6 , 0 6}$ & $\mathbf{9 1 , 0 9}$ & 333,75 & - \\
\hline
\end{tabular}

Fonte: Elaborado pelos autores com base no Portal da Transparência da União (2020). Valores em preços constantes pelo índice Geral de Preços Médios (IGPM) de dezembro de 2019.

O que chama atenção na Tabela 3 são os dados de valores empenhados, liquidados e pagos ao PTC até 2016, bem como o período pós 2016. Isso provavelmente está ligado a alteração no Governo Federal com a saída da ex presidente Dilma Roussef. Após Michael Temer assumir a presidência, alteram-se os rumos da política social e econômica do governo e o PTC entra em stand by, pois seu decreto de criação não foi revogado ou extinto, mas também não houve novas ações e injeções de recursos. Apenas 20,8\% do montante empenhado entre 2014 e 2019 foram efetivamente pagos ao programa, totalizando pouco mais de 91 milhões em todo o período, mostrando que o valor médio pago a cada PTC foi de 750 mil, cerca de 125 mil por ano por território. É um valor bastante pequeno ao verificar que alguns territórios congregam diversos municípios e também um valor reduzido em relação aos montantes já disponibilizados entre 2007 e 2013 apenas para apoio ao PTC via PTDRS.

É importante destacar que os valores dos restos a pagar, estiveram ativos até 2019, são aqueles recursos que foram empenhados, mas não liquidados durante os exercícios anteriores, ficando para exercícios futuros. Estes restos a pagar são os únicos e últimos indícios do funcionamento do PTC no Brasil. Isso nos leva a questionar, se haverá continuidade desta política pública territorial? Como será operacionalizada, será um programa diferente? A possíveis respostas para esses e outros questionamentos estão por vir com pesquisas em andamento e novos estudos sobre o próximo passo da política territorial no Brasil. Há ainda territórios que foram ativados pelo PTC e mesmo com o fim da política permanecem com algum grau de articulação via outras instituições e atores. Talvez seja esta estratégia o futuro para incitar novas propostas de desenvolvimento e inclusão social nos territórios. 
4.2 Estados beneficiados e processos de desenvolvimento estimulados

A abrangência do PTC é nacional. Os 120 territórios estão espalhados em toda malha brasileira e as vezes alguns territórios fazem parte de regiões e Estados diferentes. Os dados a seguir da Tabela 4, foram extraídos do conjunto de dados principal do programa de governo 22 entre 2014 e 2019, porém, classificou-se os montantes por Estados ao analisar cada ação separadamente e excluiu-se rubricas federais sem vínculo com Estados específicos.

Há uma dificuldade em acesso aos dados financeiros por território e por Estado separadamente. Existem estudos realizados separadamente ou em territórios selecionados que possuem dados completos, um exemplo bem elaborado é o trabalho de Cazella, Zimmermann e Leite (2013) que fizeram uma elucidação sobre entraves e avanços na política de desenvolvimento territorial do PTC ao avaliarem 6 territórios selecionados com base em dados extraídos pelo Relatório de Execução do PTC em 2010. Importante ressaltar que estes relatórios não mais se encontram disponíveis para acesso público via portal do PTC ou outro órgão orçamentário, provavelmente, devido ao fato de que a política do PTC foi congelada a partir de 2016, cumprindo apenas o compromisso de restos a pagar até 2019. Os montantes são apresentados na Tabela 4. 
Tabela 4 - Valores em milhões de reais por Estados, de 2014 a 2016, em dezembro de 2019 inflacionados pelo IGPM.

\begin{tabular}{|c|c|c|c|c|}
\hline Região & Estados & Empenhados & Pagos & Restos Pagar \\
\hline \multirow{3}{*}{ sul } & PR & 0 & & 88,3 \\
\hline & RS & 78,9 & 40,1 & 71,4 \\
\hline & SC & 54,3 & 4,0 & 47,8 \\
\hline Subtotal & & 133,2 & 44,1 & 207,5 \\
\hline \multirow{3}{*}{ Sudeste } & MG & 4,3 & 1,0 & 1,1 \\
\hline & RJ & 0,0 & 0,0 & 5,1 \\
\hline & SP & 48,8 & 41,1 & 7,3 \\
\hline Subtotal & & 53,2 & 42,1 & 13,6 \\
\hline \multirow{3}{*}{$\begin{array}{c}\text { Centro- } \\
\text { Oeste }\end{array}$} & DF & 293,0 & 30,4 & 217,8 \\
\hline & GO & 4,6 & 1,6 & 2,7 \\
\hline & MS & 120,4 & 7,1 & 66,9 \\
\hline Subtotal & & 418,1 & 39,1 & 287,4 \\
\hline \multirow{5}{*}{ Norte } & $A C$ & 106,7 & 0,0 & 56,8 \\
\hline & AM & 0,0 & 0,0 & 2,4 \\
\hline & $A P$ & 0,0 & 0,0 & 0,1 \\
\hline & RO & 0,0 & 0,0 & 31,1 \\
\hline & PA & 0,0 & 94,3 & 575,0 \\
\hline \multirow[t]{4}{*}{ Subtotal } & & 106,7 & 94,3 & 665,5 \\
\hline & $A L$ & 118,3 & 48,1 & 59,8 \\
\hline & $\mathrm{BA}$ & 0,0 & 15,5 & 0,0 \\
\hline & MA & 0,0 & 6,1 & 158,2 \\
\hline \multirow[t]{4}{*}{ Nordeste } & PB & 325,4 & 249,7 & 84,1 \\
\hline & PE & 86,6 & 57,0 & 23,5 \\
\hline & $\mathrm{RN}$ & 20,7 & 12,3 & 8,0 \\
\hline & SE & 191,1 & 74,9 & 99,2 \\
\hline Subtotal & & 742,1 & 463,5 & 432,7 \\
\hline
\end{tabular}

Fonte: Elaborado pelos autores com base no Portal da Transparência da União (2020). Valores em preços constantes pelo índice Geral de Preços Médios (IGPM) de dezembro de 2019. *Para os Estados do Ceará, Espírito Santo, Mato Grosso, Piauí, Roraima e Tocantins não há dados disponíveis.

Conforme exposto na Tabela 4, o valor dos montantes empenhados, pagos e os restos a pagar não são exatos. Uma das respostas pode estar relacionada ao fato de que valores tenham sido empenhados ou pagos por órgãos federais diretos, sem passar pela gestão de órgãos estaduais. Ainda, alguns dados chamam atenção principalmente no que diz respeito aos restos a pagar que foram pagos, em que alguns Estados, como Amazonas, Amapá, Paraná, Rio de Janeiro e Rondônia apresentam valores recebidos, mas não apresentam valores empenhados ou pagos entre 2014 e 2019. Este fato pode ser explicado caso estes Estados tenham realizado empenhos e pagamentos entre 2008 e 2013 e após esse período somente ter saldos a receber, porém, como a análise verificou cada ação individual, para cada uma 
deveria haver o valor do empenho, pagamento e se houvesse restos a pagar, caso contrário pode incorrer em uma situação em que uma ação foi empenhada e paga com recursos de ações distintas.

Outros valores que são importantes para esta análise, são os repasses aos Estados do Pará e Sergipe, totalizando em torno de 9 e 7 milhões respectivamente, e, principalmente, o valor pago neste período ao Estado da Paraíba, um montante de quase 25 milhões, mais que duas vezes superior ao segundo maior Estado, que foi o Pará. Os maiores repasses foram aos Estados da Região Nordeste, como já explicado anteriormente, região em que há maior incidência de municípios com baixo dinamismo econômico e desigualdades sociais.

De modo macrorregional, os dados evidenciam que a Região Sul registrou um volume moderado de montante empenhado, porém menos da metade foi empenhado e num segundo momento os valores de "restos a pagar pagos" foram superiores ao empenhado e pago. Os dados disponíveis ainda mostram o Paraná como Estado que não teve valores empenhados e pagos, mas somente restos a pagar. Isso não representa que o PTC não estava funcionando no Estado, mas que houve equívoco no registro dos dados ou os valores para as ações do PTC no Estado foram canalizados via outro programa de governo, já que os dados não mostram repasses exclusivos via PTC.

A Região Sudeste foi pouco relevante ao se considerar o total dos montantes destinados, puxado basicamente pelo Estado de São Paulo. Dados que chamam bastante atenção foram os montantes da Região Centro-Oeste, que tiveram valores consideráveis empenhados e pagos, puxados basicamente pelo DF. A política do PTC é voltada para territórios de baixo dinamismo socioeconômico, fato que exclui a capital federal de sua abrangência. Possivelmente os valores referentes ao DF são o que os ministérios possuem para direcionar. Mas cabe a reflexão: Porque estes valores não foram destinados aos Estados/territórios, pois são neste que ocorre o desenvolvimento territorial? A concentração desses recursos empenhados e pagos no DF mostram também, que o desenvolvimento nem sempre está chegando para aqueles que realmente se enquadram nos objetivos iniciais do PTC.

As Regiões Norte e Nordeste acabam por receber o maior efetivo dos montantes do PTC ao longo do tempo, o fato lógico está relacionado aos elevados níveis de pobreza e vulnerabilidade social destas regiões, excetuando-se algumas cidades e regiões mais dinâmicas. Isso evidencia que o PTC está de acordo com o que prezam os princípios das políticas territoriais, em atender principalmente regiões vulneráveis socioeconomicamente e historicamente.

De forma geral, ressalta-se que todos esses valores destinados via direta de ministérios e órgãos federais ou operacionalizados e descentralizados via órgãos estaduais, devem objetivar a melhoria na qualidade de vida da população residente nestes territórios. Portanto, o Estado é um indutor do desenvolvimento, criando e ampliando o acesso desses municípios aos circuitos mercadológicos, ou pelo menos, deveria atuar dessa forma.

Nesta direção, optou-se em sintetizar, a partir das 952 ocorrências entre 2014 e 2019, quais foram às ações com maior importância pelo PTC, visando em seguida, discutir quais processos de desenvolvimento territorial que foram gerados a partir destes investimentos, de acordo com os dados da Tabela 5. 
Tabela 5 - Ações do PTC entre 2014 e 2019.

\begin{tabular}{|c|c|c|c|c|c|c|}
\hline Ações & $N^{\circ}$ ações & $\begin{array}{l}\mathrm{Fi}^{*} \% \\
\text { Ações }\end{array}$ & $\begin{array}{c}\mathrm{Fi} \% \\
\text { Empenhado }\end{array}$ & $\begin{array}{c}\mathrm{Fi} \% \\
\text { Liquidado }\end{array}$ & $\begin{array}{l}\text { Fi \% } \\
\text { Pago }\end{array}$ & $\begin{array}{c}\text { Fi \% } \\
\text { Restos } \\
\text { pagos }\end{array}$ \\
\hline $\begin{array}{c}\text { Assistência técnica e } \\
\text { extensão rural para reforma } \\
\text { agraria }\end{array}$ & 524 & $55 \%$ & $58 \%$ & $79 \%$ & $87 \%$ & $52 \%$ \\
\hline $\begin{array}{c}\text { Apoio ao desenvolvimento } \\
\text { sustentável de territórios } \\
\text { rurais }\end{array}$ & 177 & $19 \%$ & $32 \%$ & $15 \%$ & $\%$ & $37 \%$ \\
\hline $\begin{array}{c}\text { Apoio a organização } \\
\text { econômica e promoção da } \\
\text { cidadania de mulheres rurais }\end{array}$ & 102 & $11 \%$ & $3 \%$ & $6 \%$ & $\%$ & $4 \%$ \\
\hline $\begin{array}{l}\text { Assistência técnica e } \\
\text { extensão rural para } \\
\text { agricultura familiar }\end{array}$ & 65 & $7 \%$ & $4 \%$ & $1 \%$ & $1 \%$ & $5 \%$ \\
\hline $\begin{array}{l}\text { Apoio a projetos de P\&D para } \\
\text { tecnologias sociais, assistivas, } \\
\text { extensão tecnológica e de } \\
\text { inovação para inclusão social } \\
\text { e desenvolvimento } \\
\text { sustentável }\end{array}$ & 38 & $4 \%$ & $1 \%$ & - & - & $1 \%$ \\
\hline $\begin{array}{c}\text { Desenvolvimento da } \\
\text { infraestrutura pesqueira e } \\
\text { aquícola }\end{array}$ & 24 & $3 \%$ & $2 \%$ & - & - & $1 \%$ \\
\hline $\begin{array}{l}\text { Fomento à produção } \\
\text { pesqueira e aquícola }\end{array}$ & 22 & $2 \%$ & $1 \%$ & - & - & $1 \%$ \\
\hline Total & 952 & $100 \%$ & $100 \%$ & $100 \%$ & $100 \%$ & $100 \%$ \\
\hline
\end{tabular}

Fonte: Elaborado pelos autores. * Fi: Frequência.

Nota-se que do total de investimentos, mais da metade foram direcionados para assistência técnica e extensão rural para a reforma agrária, com cerca de $55 \%$ das ações, totalizando $87 \%$ dos recursos pagos. Este fato evidencia que o foco principal do PTC está no meio rural. As ações são basicamente de fomento a dinamização da agricultura familiar, assistência técnica, reforma agrária, desenvolvimento de infraestrutura, apoio à cidadania de mulheres rurais e apoio ao desenvolvimento rural sustentável. No meio rural, os recursos do PTC foram bem vistos e sentidos pelos atores pertencentes aos territórios, com as ações de promoção ao desenvolvimento rural de áreas de baixo dinamismo econômico mostrando-se relevante para amenizar a situação desses territórios.

Outros resultados importantes estão nas ações ao desenvolvimento sustentável dos territórios rurais, que é uma preocupação do PTC verificada no seu instrumento de planejamento, o PTDRS. Nesta área, foram 177 ações, porém, dos $32 \%$ de montantes empenhados para tal fim, somente $7 \%$ foram efetivamente pagos. A desigualdade de gênero, presente no meio rural, também foi contemplada por ações de apoio à organização, economia e promoção da cidadania de mulheres rurais, totalizando 102 ações, cerca de $11 \%$ do total de ocorrências encontradas, todavia, dos valores totais empenhados, estas ações receberam apenas $5 \%$ dos recursos pagos. 
Diante do exposto, salienta-se que o desenvolvimento de uma região ou território deve contemplar a ampliação de acesso a bens, serviços e melhoria na qualidade de vida e, certamente, os aspectos supracitados neste PTC, permitiram em alguma proporção esse fenômeno, especialmente no âmbito rural.

Por outro lado, percebe-se também que esse foco no rural deixa de lado algumas questões urbanas dos municípios que atualmente dependem exclusivamente do comércio e serviços e, também, possuem baixo dinamismo econômico. Logo, é necessário perceber que um território é composto por uma diferente gama de atores, não somente rurais, mas urbanos também, esse fato pode ter sido menosprezado pelo PTC. O desenvolvimento não pode ser focalizado em uma dicotomia rural versus urbano, mesmo considerando a hipótese que a pobreza no meio rural possa ser mais predominante do que em regióes urbanizadas. Caso o desenvolvimento seja exclusivo, e não inclusivo, de forma geral, poderá se tornar um processo que gerará mais desigualdades que benefícios para o território. As políticas públicas para desenvolvimento territorial devem abarcar todas as regiões e atores dentro de um território.

Em relação as ações de apoio a projetos de P\&D, estas perfazem apenas $4 \%$ do total, via Ministério da Ciência Tecnologia, Inovação e Comunicações para fomento de projetos de P\&D para tecnologias sociais, assistivas, extensão tecnológica e de inovação para inclusão social e desenvolvimento.

Ainda nesta discussão, não se observa outros tipos de investimentos, relacionados, por exemplo, ao comércio e serviços, habitação urbana, saneamento básico, alimentação escolar e outras tantas ações que poderiam estar contidas no rol do PTC e com verbas destinadas para tais fins. O PTC chegou ao fim em 2019, ou pelo menos em um processo de "congelamento", sendo que a partir de 20200 Brasil não conta com um plano de desenvolvimento territorial integrado em âmbito federal e a grande maioria dos territórios de baixo dinamismo econômico do PTC, seja rural ou urbano, continuam em uma situação similar.

Cada território elege suas prioridades a partir do Colegiado Territorial e da elaboração, sequência e implantação das ações do PTDRS de cada território. Logo, torna-se tarefa desafiadora aos pesquisadores, mensurar quais impactos no desenvolvimento têm sido gerados pelo PTC. Neste sentido, os dados apresentados evidenciam que nesta política pública se foca no desenvolvimento territorial rural, quase que exclusivamente, mesmo havendo uma outra política específica de Desenvolvimento Sustentável para Territórios Rurais (PRONAT) que contemplam 242 territórios e 2500 municípios (DRUCIAKI; NYCHAI, 2017).

Desde a sua implementação, os Territórios da Cidadania receberam recursos federais para ampliar a qualidade de vida e dinamismo econômico em todas as regiões brasileiras, com maior ênfase no Norte e Nordeste. Os valores encontrados neste trabalho, direto do Portal da Transparência da União, diferem de outros encontrados na literatura, os montantes efetivamente pagos foram menores. Verifica-se que alguns Estados concentraram os recursos do PTC por aglomerarem grande contingente de municípios em Estado de baixo desenvolvimento. A partir de 2016 cessaram os empenhos e pagamentos de novos repasses ao PTC, deixando aos anos subsequentes, até dezembro de 2019, apenas os restos a pagar. 


\section{Considerações finais}

O desenvolvimento territorial vem se tornando cada vez mais objeto de estudo na literatura acadêmica, devido a sua importância de aplicabilidade local visando entender as interfaces do desenvolvimento levando em consideração todas às suas características e, assim, amplificando o potencial de desenvolvimento de uma região. Mesmo assim, ainda é um campo a ser explorado, principalmente em países como o Brasil, o qual possui uma área territorial bastante grande, historicamente desigual e desproporcional, gerando um país com problemas territoriais severos a serem dirimidos e tratados.

Neste sentido, o PTC como política pública do Governo Federal, busca atenuar as disparidades sociais e econômicas em municípios e territórios brasileiros por meio de repasses de verbas destinadas a ações específicas elegíveis e priorizadas em Colegiados Territoriais de participação democrática. Neste sentido, o presente artigo buscou responder questionamentos referentes ao montante investido no PTC desde sua criação pelo decreto de 25 de fevereiro de 2008, quais foram os Estados mais beneficiados, bem como quais ações foram priorizadas em termos de desenvolvimento territorial.

Destarte, apesar da dificuldade na obtenção de dados fidedignos em fontes oficiais, encontrou-se resultados divididos em dois períodos, sendo o primeiro de 2007 até 2013 e, o segundo, entre 2014 até 2019. O primeiro período encontrou recursos destinados a ações de apoio ao PTC e a elaboração e gestão do PTDRS. Em média, os recursos empenhados somaram 26,2 milhões e apenas 14,6 milhões pagos. $\mathrm{O}$ ano com maior volume de recursos efetivamente pagos foi $2010 \mathrm{com}$ cerca de 40,2 milhões e o menor de 2013 com apenas 300 mil referentes ao valor pago. De 2007 a 2013 o montante total pago foi de 102,6 milhões, valor que difere do encontrado na literatura por alguns autores.

Segundo Favareto (2010), para 2008 para o PTC estava orçado em 12,9 bilhões. Já Galvanese (2018), afirma que o PTC realizou 180 ações em 2009, investindo cerca de 23 bilhões de reais. Essa incongruência pode estar no fato de que neste trabalho os valores utilizados foram exclusivamente retirados do Portal da Transparência da União e não de trabalhos ou fontes ligadas aos ministérios envolvidos no respectivo período analisado. Outra explicação pode ser o fato de haver recursos federais empenhados diretos aos PTC sem passar pelo programa específico do governo.

O segundo período de 2014 a 2019 evidencia a fase final do PTC, em que os investimentos diminuem e os valores empenhados, liquidados e pagos se findam em 2016, muito provavelmente, ligado a alteração no governo brasileiro com a troca presidencial. Nos anos de 2016 até 2019, foram pagos somente os restos a pagar, totalizando cerca de 333,7 milhões. Os Estados mais beneficiados foram Paraíba, Pará, Sergipe e Pernambuco, devido aos municípios das Regiões Nordeste e Norte possuírem menores índices de qualidade de vida.

Os processos de desenvolvimento gerados a partir dos investimentos do PTC foram simplificados pelas ações desempenhadas durante o período. A ação com maior incidência entre as 952 ocorrências do período de 2014 a 2019, foi a assistência técnica e a extensão rural para a reforma agrária, com 524 ocorrências, cerca de $55 \%$ do total de ações realizadas. Posteriormente, foram verificadas ações 
de apoio ao desenvolvimento sustentável, com 177 ocorrências e, o apoio a organização econômica e a promoção da cidadania de mulheres rurais com 102 ocorrências. Ressalta-se que estes dois últimos, apesar da quantidade de ocorrências, pagaram efetivamente, somente $7 \%$ e $5 \%$ do total.

Em síntese, verifica-se que os montantes do PTC foram, em sua grande parte, destinados a ações no meio rural e seus recursos possuem disparidades graves entre os valores empenhados e aqueles pagos, bem como quanto aos restos a pagar que efetivamente foram pagos. Logo, algumas questões para reflexão surgem neste contexto: o planejamento territorial brasileiro é exclusividade rural? A pobreza, desigualdade de renda e disparidade social não ocorre em territórios urbanos? Os municípios conseguiram superar ou melhorar sua condição de pobreza e desigualdade a partir do PTC?

Ademais, observa-se nas políticas públicas que o Brasil inicia o ano de 2020 sem uma agenda de desenvolvimento territorial organizada, seja nos moldes do PTC ou baseado em outro programa. Neste sentido, é necessário pensar em novas políticas de desenvolvimento territorial para o Brasil, evitando o aprofundamento ainda maior das desigualdades e dualidades entre o rural e o urbano. Além disso, urge que este tipo de política incorpore a multiplicidade dos atores sociais que compõe os territórios, além dos princípios da sustentabilidade, tão importantes ao desenvolvimento territorial.

\section{REFERÊNCIAS}

ANASTASIA, B.; CORÒ, G. Evoluzione di un'economia regionale. II Nordest depo il sucesso. Portogruaro: Ediciclo, 1996.

BACELAR, T. Nordeste: desenvolvimento recente e perspectivas. In: GUIMARÃES, Paulo Ferraz et al. (Org.). Um olhar territorial para o desenvolvimento: Nordeste. Rio de Janeiro: Banco Nacional de Desenvolvimento Econômico e Social, 2014. pp. 540-560.

BERDEGUÉ, J.; FAVARETO, G. Balance de la experiencia latinoamericana de desarrollo territorial rural y propuestas para mejorarla. In: Berdegué. J. Christian, C. Favareto, A. Quince años de desarrollo territorial rural en América Latina: ¿quéos muestra la experiencia? / - 1a ed. - Ciudad Autónoma de Buenos Aires: Teseo, 2020.

\section{BOISIER, S., El desarrollo territorial a partir de la construcción de capital}

sinergético. Curso internacional Ciudad Futura II, Rosário. 2004.

BRANDÃO, C. Território \& Desenvolvimento: as múltiplas escalas entre o local e o global. Campinas: Ed. Unicamp, 2007.

BRASIL. Decreto de 25 de fevereiro de 2008. Institui o Programa Territórios da Cidadania e dá outras providências. Diário Oficial da União - Seção 1 - 26/2/2008, Página 1. Brasília, 2008. 
BUTTO, A.; BEMERGUY, E. A Cidadania nos Territórios: o olhar da Coordenação Executiva do Programa Territórios da Cidadania sobre o Estado e as mudanças na Agenda de Desenvolvimento Nacional. In: CAVALCANTI, J. S. B; WANDERLEY, M. N. B.; NIEDERLE, P. A. (Orgs.). Participação, território e cidadania: um olhar sobre a política de desenvolvimento territorial no Brasil. Recife: Editora UFPE, 2014.

CAPELLO, R. Regional economics in its 1950's: recent theoretical directions and future challenges. Ann Reg Sci. 42, 747-767 (2008).

CAZELA, A. A.; ZIMMERMANN, S. A.; LEITE, S. P. A gestão do Programa Territórios da Cidadania no Brasil: análise das ações e políticas implementadas. Perspectivas Rurales. Nueva época, Año 11, $N^{\circ} 22$.

DRUCIAKI, F. P. Desenvolvimento territorial: A associação do centro do Paraná AMOCENTRO. Programa de Pós Graduação em Desenvolvimento Regional e Agronegócio PGDRA (Dissertação de mestrado). Toledo: Unioeste, 2016.

DRUCIAKI, F. P. Localização dos Territórios da Cidadania nas Macrorregiões brasileiras. Guarapuava: [s. n.], 2012. 1 mapa, colorido. Escala 1:500. Elaborado com base IBGE (2010).

DYE, T. D. Understanding Public Policy. Englewood Cliffs, N.J.: PrenticeHall, 1984. ESCOBAR, A. O lugar da natureza e a natureza do lugar: globalização ou pósdesenvolvimento? In: LADER, E. (Org). A colonialidade do saber: eurocentrismo e ciências sociais. Ciudad Autônoma de Buenos Aires, Argentina: Colección Sur Sur, CLACSO, 2005.

FAVARETO, A. Retrato das políticas de desenvolvimento territorial no Brasil. Serie Documentos de Trabajo. Santiago do Chile: 2009.

FAVARETO et al. Quince años de desarrollo territorial rural. La experiencia de los programas y planes del estado de Bahía, Brasil. In: BERDEGUÉ, J.; CHRISTIAN, C.; FAVARETO, A. Quince años de desarrollo territorial rural en América Latina: ¿quéos muestra la experiencia? 1a ed. - Ciudad Autónoma de Buenos Aires: Teseo, 2020.

FEDERAÇÃO DAS INDÚSTRIAS DO RIO DE JANEIRO. IFDM 2018: Indice Firjan de desenvolvimento municipal. Ano base 2016. Rio de Janeiro: Firjan, 2018.

FUNDAÇÃO GETÚLIO VARGAS. Índice Geral de Preços - Mercado. 2020. Disponível em: < https://portalibre.fgv.br/estudos-e-pesquisas/indices-de-precos/igp > Acesso em: 5 Jan. 2020.

FURTADO, C. O. Mito do desenvolvimento econômico. Rio de Janeiro: Paz e Terra, 1973.

GALVANESE, C. S. Paradigmas do planejamento territorial em debate: Contribuições críticas a um campo científico emergente. (Tese doutorado). Programa de Pós- 
Graduação em Gestão do Território, Universidade Federal do ABC. São Bernardo do Campo, 2018.

GIL, A. C. Como elaborar projetos de pesquisa. 5. ed. São Paulo: Atlas, 2010.

FERRERA DE LIMA, J. Geoeconomie et Developpement Regional. 01. ed. Paris: Publibook, 2012. v. 01. 124p

JEAN, B. Le développement territorial : une discipline scientifique emergente. Sciences des territoires, Perspectives québécoises, Québec, Presses de I'Université du Québec, pp. 283-313. 2008.

Lasswell, H.D. Politics: Who Gets What, When, How. Cleveland, Meridian Books: 1936.

LYNN, L. E. Designing Public Policy: A Casebook on the Role of Policy Analysis. Santa Monica, Calif.: Goodyear. 1980.

NYCHAI, L. ; DRUCIAKI, F. P. . Rural territoriality and ICMS distribution: the case of the state of Paraná. Confins. p. 1, 2017.

MDA - BRASIL - Ministério do Desenvolvimento Agrário. Secretaria de Desenvolvimento Territorial. Sistema de gestão estratégica: Documento de referência. Brasília, 2010. Disponível em:

<http://sge.mda.gov.br/sge/doc/SGE_documento_referencia.pdf> Acesso em 4 de Maio de 2020.

PECQUEUR, B. A guinada territorial da economia global. Dossiê Economia e Sociedade. $N^{\circ} 14,2009$.

PECQUEUR, B.; BENKO, G. Os recursos do território e os territórios de recursos. Geosul. v.16, n.32, p 31-50, jul./dez. 2001.

PERROUX, F. L'économie du XXème siècle. Paris: PUF, 1994.

RULLANI, E. Più locale e più globale: verso una economia postfordista del territorio. In: BRAMANTI, A.; MAGGIONI, M. La dinamica dei sistemi produttivi territoriali: teorie, tecniche, politiche. Milano: Franco Angeli, 1997. p. 85-111.

SANTOS, M. O espaço dividido: Os dois circuitos da economia urbana dos países subdesenvolvidos. $2^{\text {a }}$ ed. São Paulo: Editora da universidade de São Paulo, 2008.

SOUZA, C. Políticas Públicas: uma Revisão da Literatura. Sociologias. Porto Alegre, v. 8, n. 16, p. 20-45, 2006.

VALENCIA, M. E. et al. Doce años del Programa Desarrollo Sustentable de Territorios Rurales del Ministerio de Desarrollo. In: BERDEGUÉ, J.; CHRISTIAN, C. FAVARETO, A. 
Quince años de desarrollo territorial rural en América Latina: ¿quéos muestra la experiencia? 1a ed. - Ciudad Autónoma de Buenos Aires: Teseo, 2020.

VELASCO, R. Los economistas em su laberinto. Madri: Taurus, 1996.

Marcos Junior Marini. Universidade Tecnológica Federal do Paraná (UTFPR) Programa de Pós-Graduação em Desenvolvimento Regional (PPGDR). E-mail marini@utfpr.edu.br

Felipe Polzin Druciaki. Universidade Estadual do Centro Oeste (UNICENTRO), Guarapuava, Paraná. E-mail - felipe_polzin@hotmail.com

Marcio Gazolla. Universidade Tecnológica Federal do Paraná (UTFPR) Programa de Pós-Graduação em Desenvolvimento Regional (PPGDR). E-mail marciogazolla@utfpr.edu.br

Christian Luiz da Silva. Universidade Tecnológica Federal do Paraná (UTFPR) Programa de Pós-Graduação em Desenvolvimento Regional (PPGDR). E-mail christiansilva@utfpr.edu.br

Como citar: MARINI, Marcos Junior et al. Desenvolvimento territorial: Uma análise sobre os recursos do Programa Territórios da Cidadania. Redes (St. Cruz Sul, Online), Santa Cruz do Sul, v. 25, p. 2616-2639, 2020. ISSN 1982-6745. doi:https://doi.org/10.17058/redes.v25io.15181.

\section{CONTRIBUIÇÃO DE CADA AUTOR}

a. Fundamentação teórico-conceitual e problematização: Marcos Junior Marini, Felipe Polzin Druciaki, Marcio Gazolla, Christian Luiz da Silva

b. Pesquisa de dados e análise estatística: Felipe Polzin Druciaki

c. Elaboração de figuras e tabelas: Felipe Polzin Druciaki

d. Fotos: não se aplica

e. Elaboração e redação do texto: Marcos Junior Marini, Felipe Polzin Druciaki, Marcio Gazolla, Christian Luiz da Silva

f. Seleção das referências bibliográficas: Marcos Junior Marini, Felipe Polzin Druciaki, Marcio Gazolla, Christian Luiz da Silva

Fontes de financiamento: CNPq; Processo - 306960/2019-2. 